\title{
الأشكال النحتية الحديثة ودورها في تطور الأشكال المعمارية المعاصرة
}

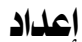 \\ د. يوسف ناصر المليفحسـ \\ أستاذ مساعد بقسم التربية الفنية \\ كلية التربية الأساسية - دولة الكويت
}

مجلة بحوث التربية النوعية ـ جامعة المنصورة

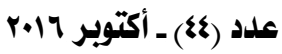




\title{
الأشكال النحتية الحديثة ودورها في تطور الأشكال المعمارية المعاصرة
}

\author{
إعداد

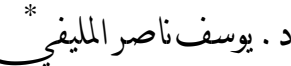

مقدمية:

النحت منــ عرفه الإنسـان هو عمليـة بنـاء سواء ككان نحتـا على الأحجـار أو تشكيلا بمهواد

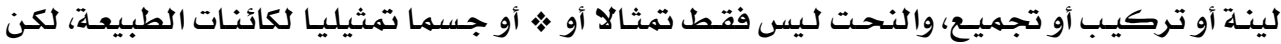

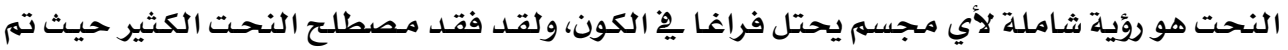

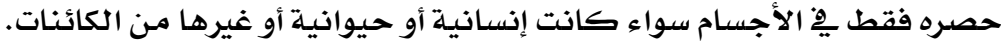

وللنحت صلة وثيقة عبر التاريخ بفكرة وجود الأبنية التي استخدمت يِ أنشطة الحياة دينية

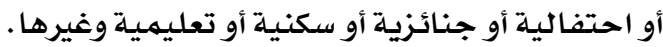

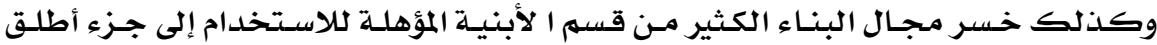

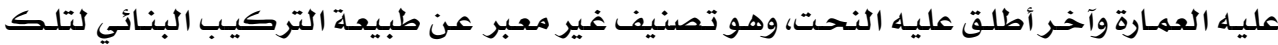

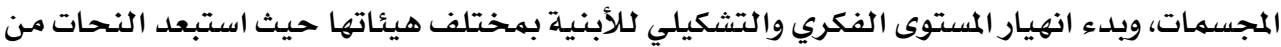
المشاركة يِّ صياغة المنطق الفكري والتشكيلي لتلك المستوب الأبنية.

والعلاقـة بـين النـحـت والعمـارة ليست على الإطـلاق جــار أو تمثثال أو حائطسا وتشكيل بـارز

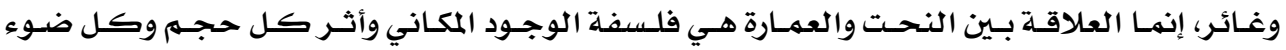
على النفس.

أصبح أقصى طموح للنحات المعاصر هو الحصول على فرصدة لتنفيذ مـا أطلق عليه مكمهلات

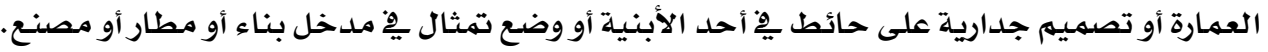
ككن يْ حقيقة الأمـر أن النحت والعمارة هما شيء واحد لا يمكن الفصل بينهما لكن الهدف هو الحصول على كيان متماسك يحقق الرءوس الفلسفية والقيم الجمالية.

ولعل العمل النحتي الكبير لمؤسسته دار التحرير شكل (1)

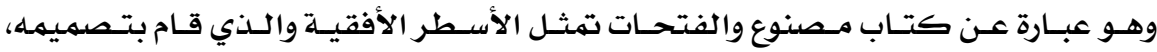

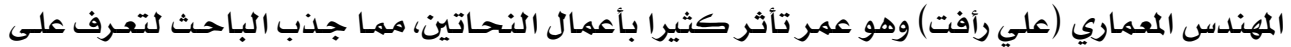

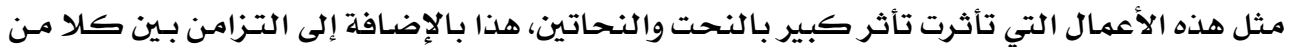

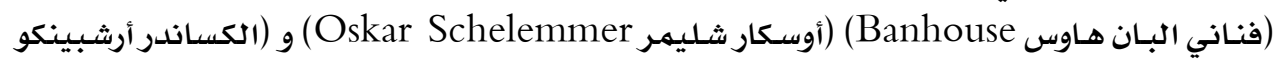

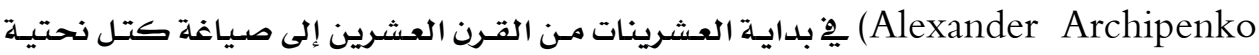

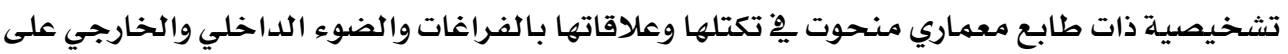




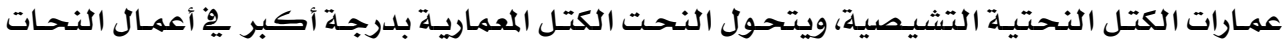

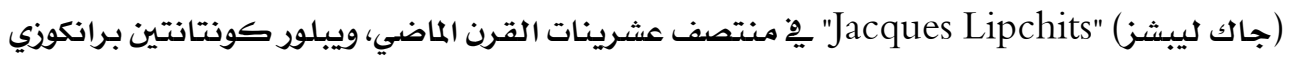

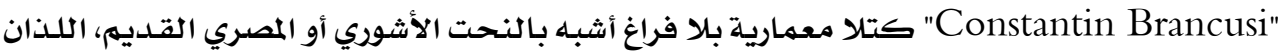

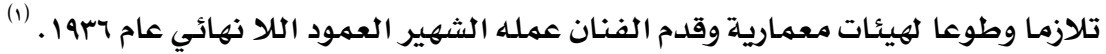
كذلك قدم لنـا (هنري مـوتي Henry Moote) أعمال نحتيـة معماريـة عضويـة التكوين،

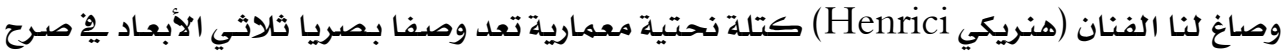
معماري للمتحف البر يطاني بلندن شكل (r) ). هذا وقد تعاون المهندس المعماري (جمال بكري) مـع عدد من الفنـانين والنحساتين مثل الفنـان

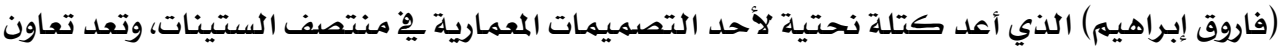

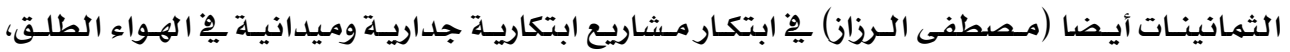

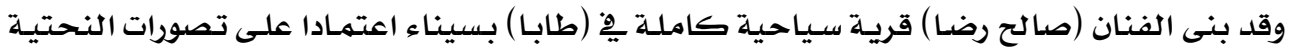

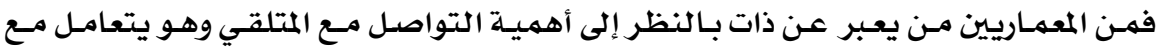

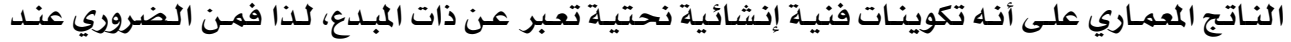

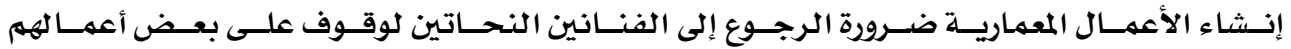
وتصميماتهم حتى تنفذ وظيفيا ويكون البناء المعماري كتلة نحتية بمقياس حقيقي ناجـح جماليا.

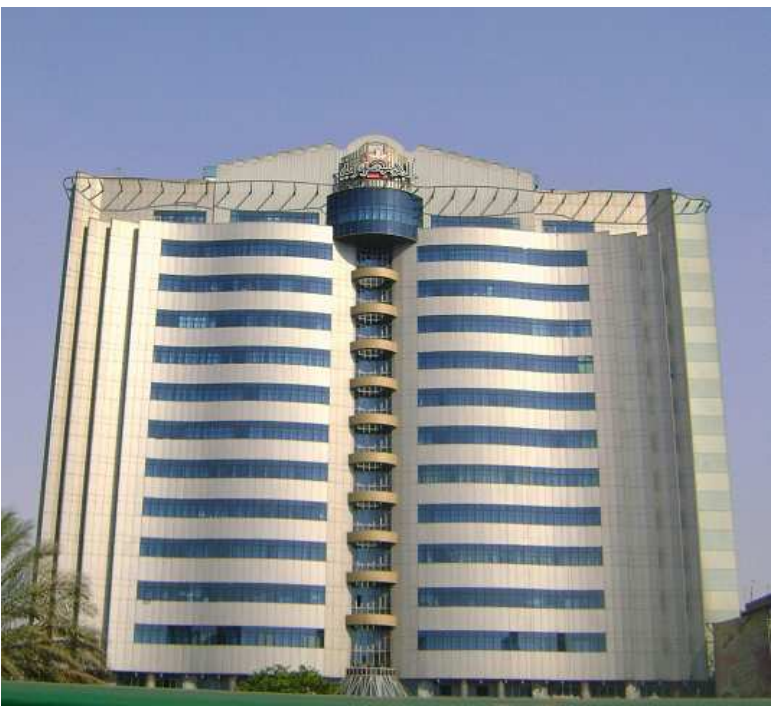

شكل (1) مؤسسة دار التحرير ( جريدة الجمهورية )

( ) مصطفى الرزاز: الخيال المعماري للنحات، كتالوج العمارة بأيدي النحاتين، قطاع الفنون التشكيلية، وزارة الثقافة، . مع (r)

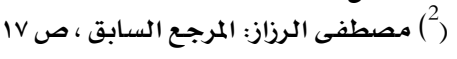




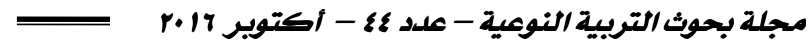

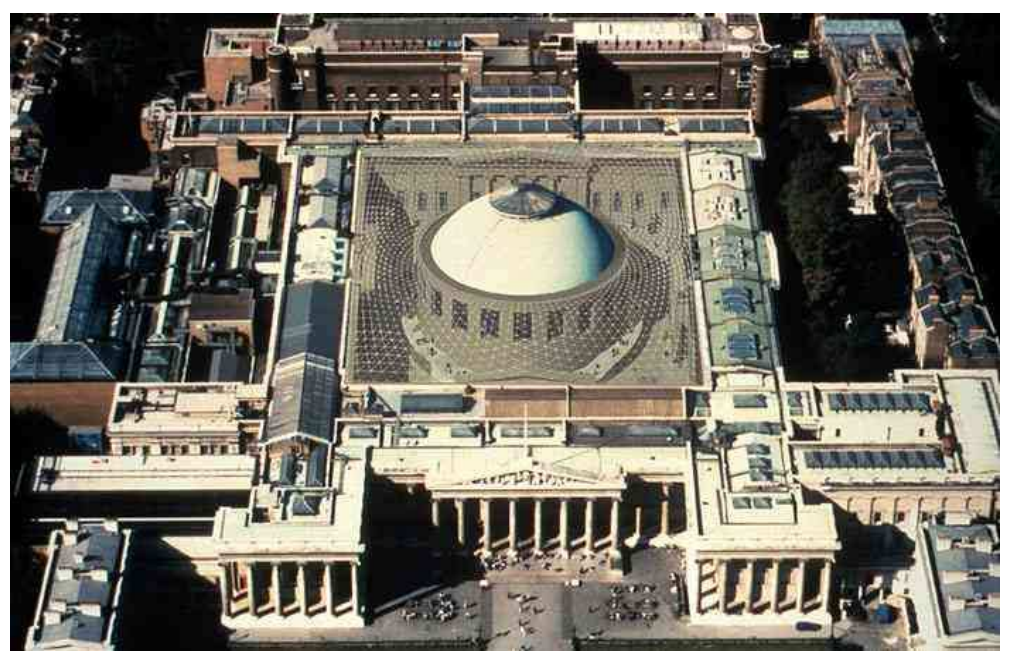

$$
\text { شكل (r) متحف الفن البريطاني ( لندن ) }
$$

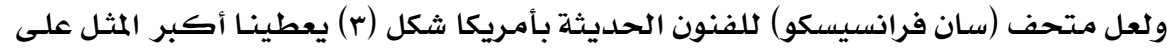

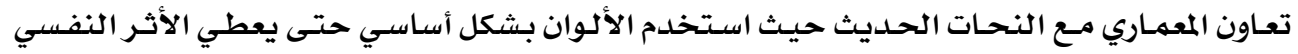

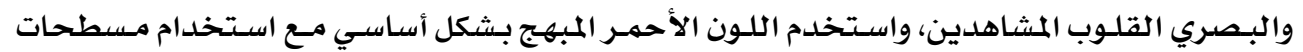

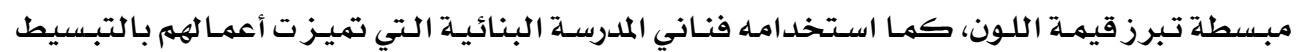

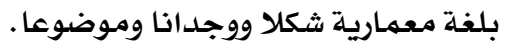

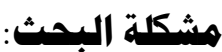

كيف يمكن الاستفادة من المنحوتات الحديثة يِّ تطوير العمارة المعاصرة؟ أهد|ف البحث:

$$
\text { 1 ـ التعرف على مفهوم كالا من النحت والعمارة. }
$$

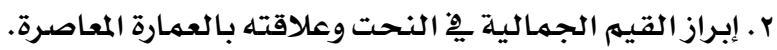

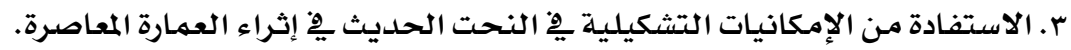
أهمية البمث: الاصتفادة من

ا ـ التعرف على العلاقة الوطيدة بين النحت والعمارة وتأثر كل منهما بالآخر وعلاقة كلا منهما

$$
\text { بالفراغ المحيط بـه. }
$$

r. الكشف عن إمكانية الاستفادة من الخامـات والأساليب والطرق النحتيـة المختلفـة لإنتاج أعمال

$$
\text { نحتية معاصرة. }
$$

م. التعرف على أهم المؤثرات التي أدت إلى تأُثير العلاقة بين النحت الحديث والعمارة المعاصرة.

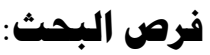

- يفترض البحث أن هناك علاقة إيجابية بين تطور العمارة المعاصرة والنحت الحديث. 
ا ـ نماذج من الأعمال المعمارية التي ارتبطت بالنحت يِّ القرن العشرين والحادي والعشرين.

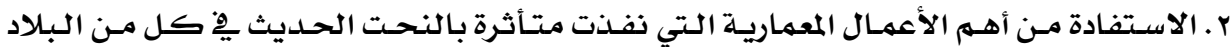

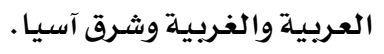

r. التعرف على بعض الفنانين الذين ارتبطت أعما لهم بالعمارة.

\section{التمام النمت والعممارة:}

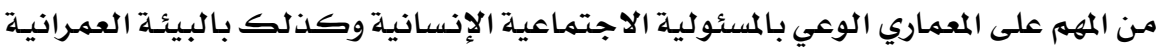

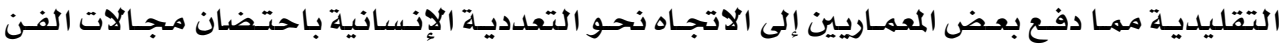

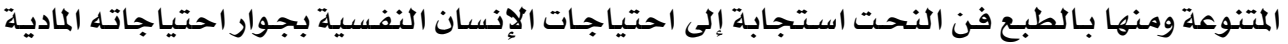

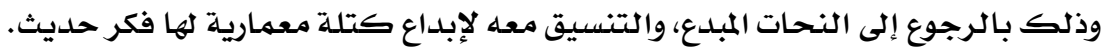

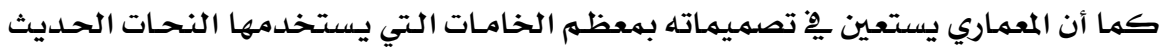

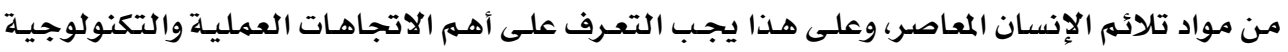

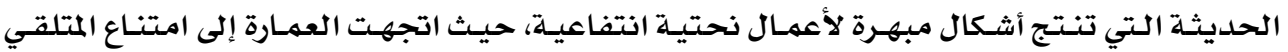

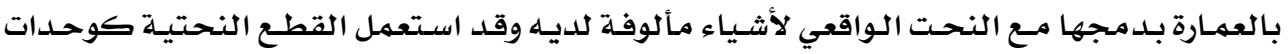

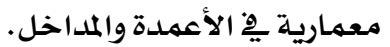

وقد كـان الفنـان المعمـاري (هرمـان فنستلين Hermean Finsterlin) تصميماته عضوية

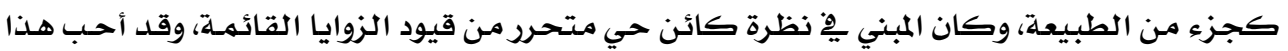

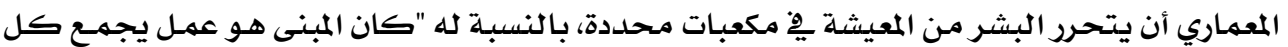

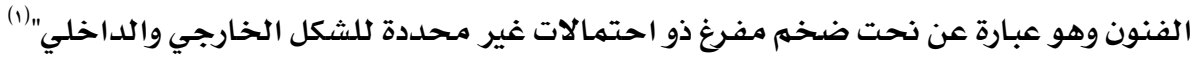
وقد ظهرت الاستمرار الفراغية المادية يِّ متحف (جوجنهايم Guggenheim Museum)

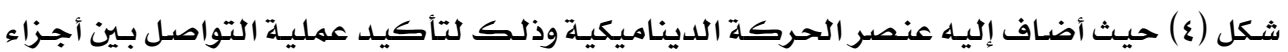

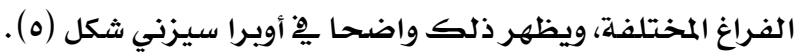
ولعل معرض العمارة بأبوي النحاتين يعكس دور النحات يِّ تطور واستحداث هيئات معماريـة

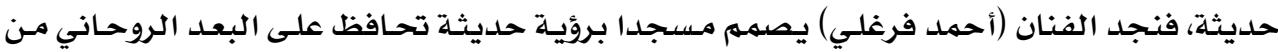

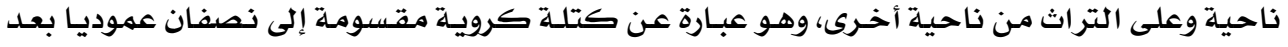

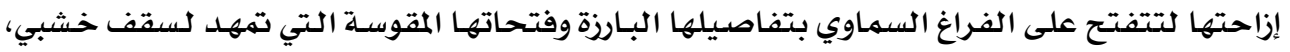

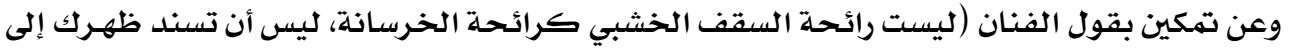

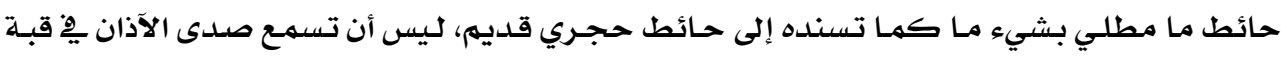

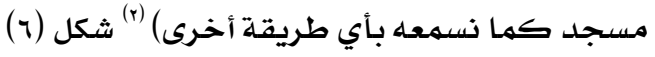

(1) Sbarp. D: Modern Atchitecture and Expressionism, Longmans, London, 1966, p98.

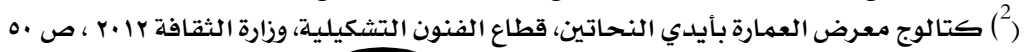


مجلة بحوث التربية النوعية - علد ع - أكتوبر r.l7

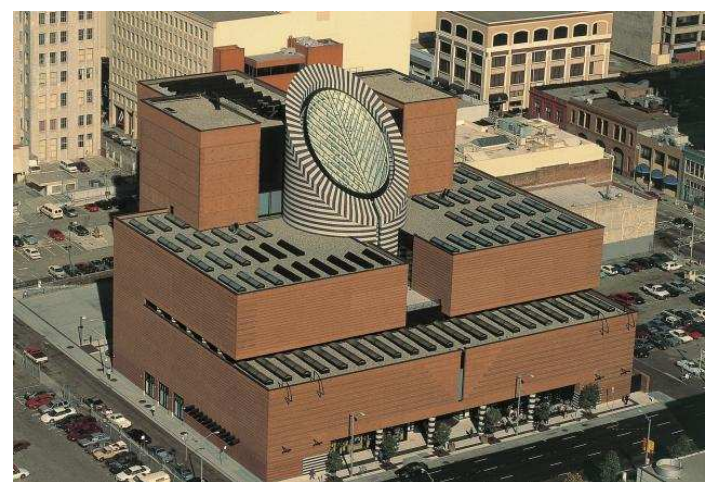

ثكل (r) متحف ( سان فرانسيسكو ) للفنون الحديثة الولايات المتحدة الامريكية

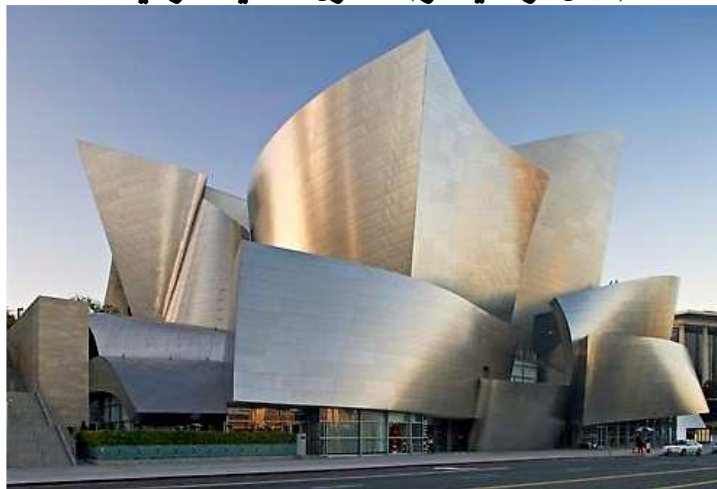

شكل (ع) متحف جوجنهايهم

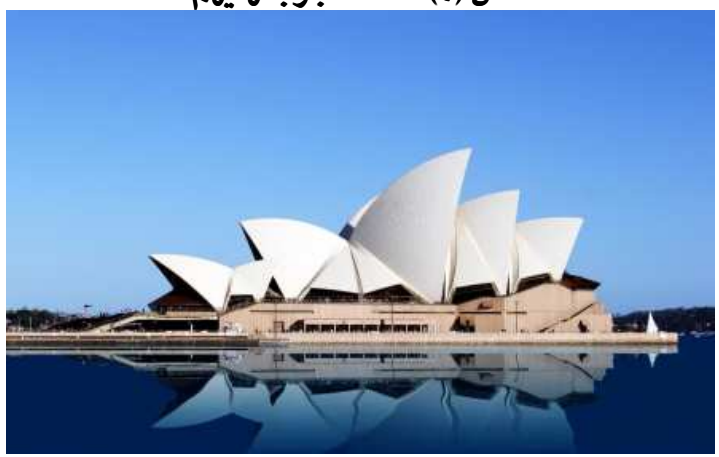

شكل (0) اوبرا سيدني ( استراذيا )

وقد دلنا الفنان (حسن كامل) لرؤيته بقوله "أنا يْ نحتي .. حلـم النحـات الدلدائم أن يـرى مـا

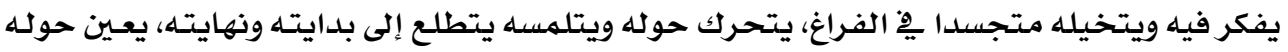

ويستمتع بنظره إليه، أنت جزء من نحتك، نحتك يحتويك" (1) شكل (v) 
أما (سعد بدر) المثال فيقدم لنا القيم البصرية للتشكيل بـين النحـت والعمـارة ِِِ عملـه شكل

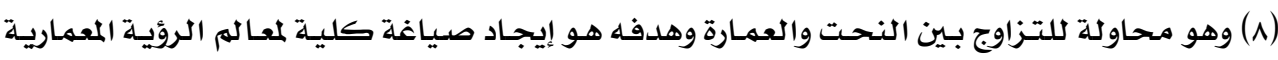

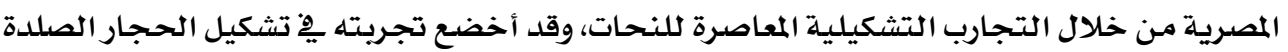
لصياغة المدينة المصرية المعاصرة.

وحول تحقيق الحلهم يقدم الفنـان (شمس الدين القرنفلسي) عمـلا يقول عنـه "كلمـا قاريـت

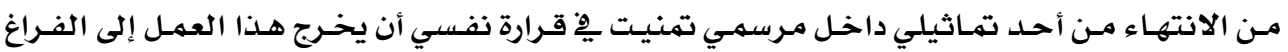

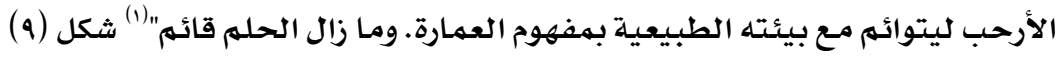
أما المثال (طارق الكومي) الذي تمثل أعماله النحتية إلى التلخيص الشديد للكيد الكتلة واختزال

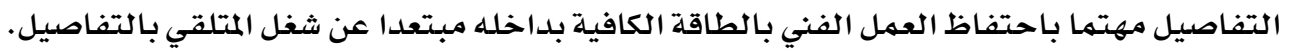

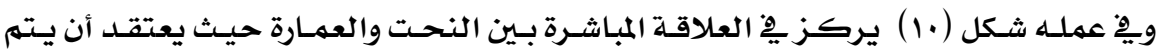

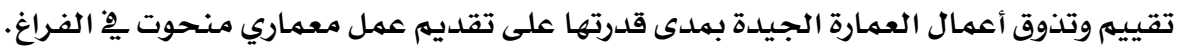

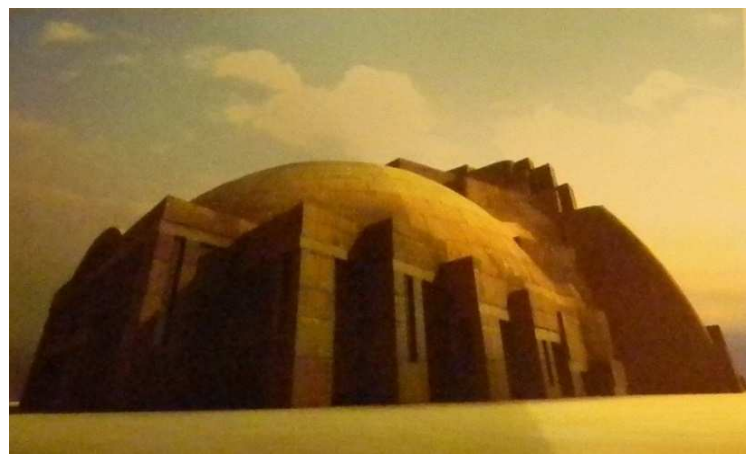

شكل (7) المثال أحمد قرعلى ( مسجد برؤية حديثة )

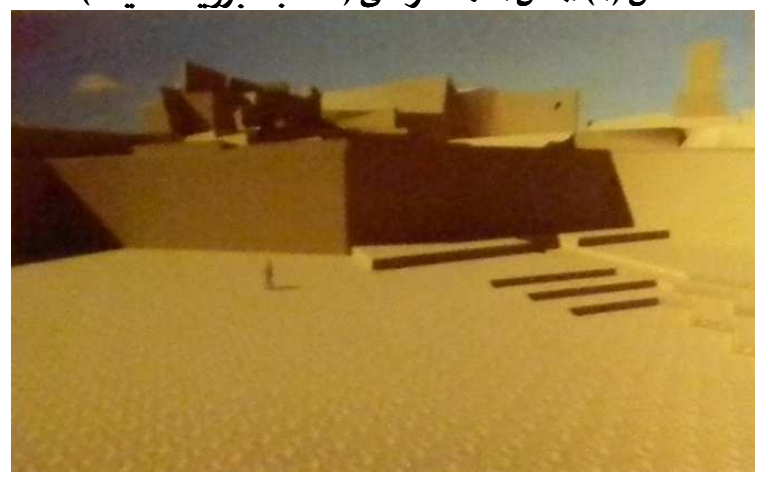

شكل (v) المثال حسن كامل ( حلم النحات )

(1) المرجع السابق، صזی. 


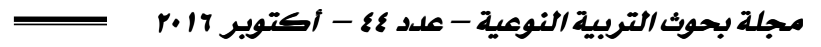

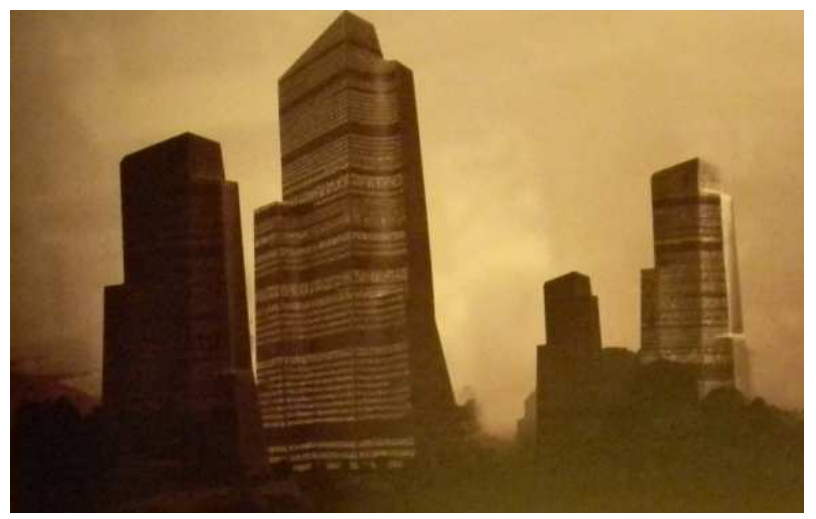

شكل ( ^) سعيد بدر (التزواج بين العمارة والنحت )

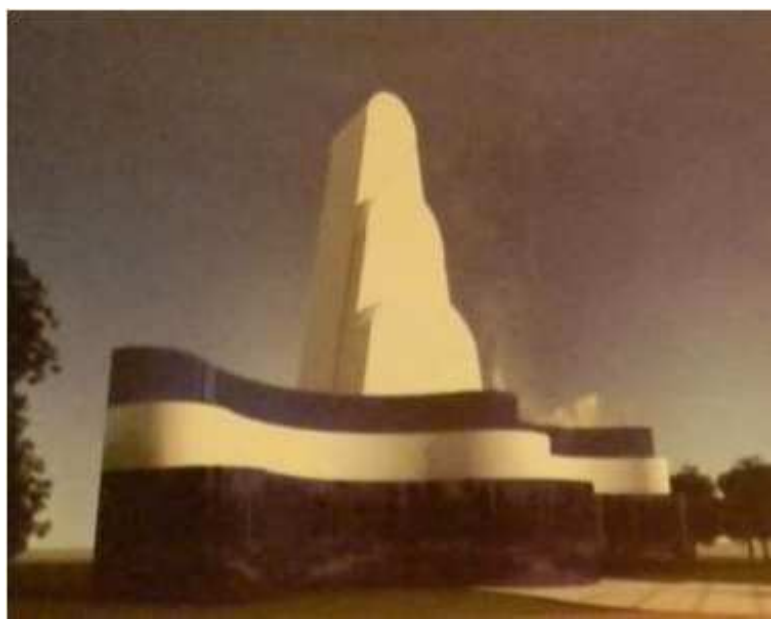

شكل (9) شمس الدين القرنفلى ( تحقيق الحلم )

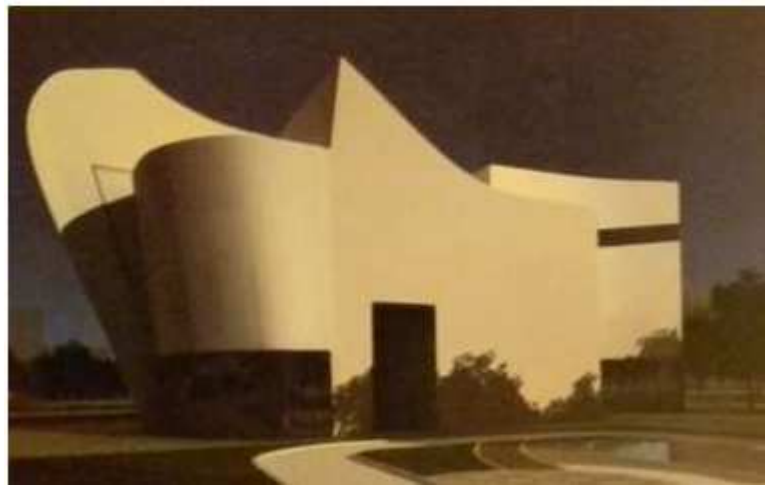

شكل ( ـ ) المثال طارق الكومي ( عمل معماري منحوت ِِ الفراغ ) 


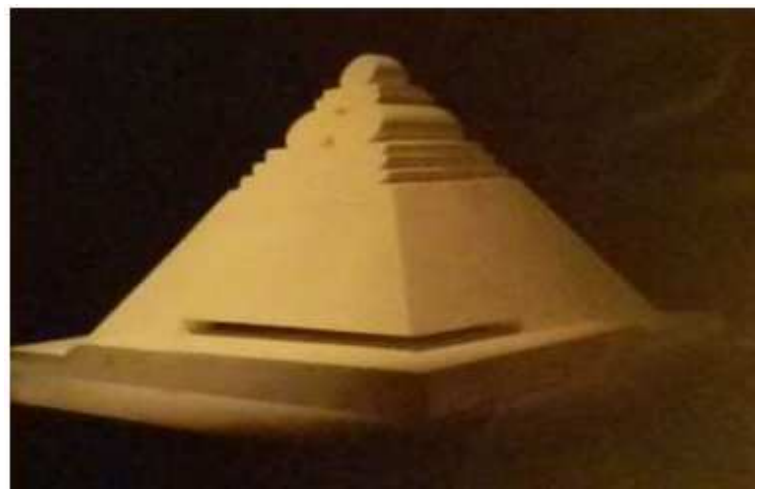

شكل (11) المثال عصام درويش ( ضوء الشمس )

ويقـدم لنـا المثال (عصام درويش) شـكل (11) رؤيسة جديـدة مبنيـة على أشـكال هندسيـية مجـردة

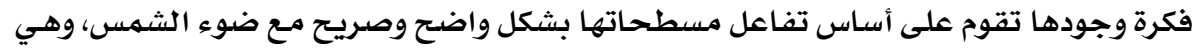

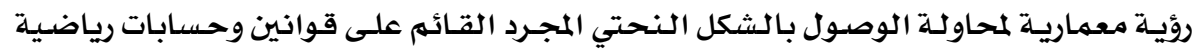

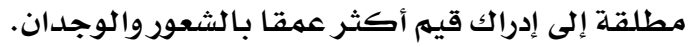

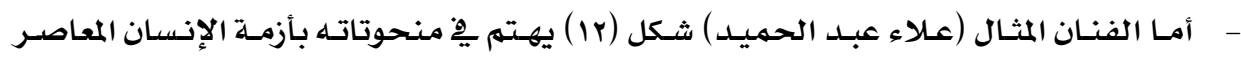

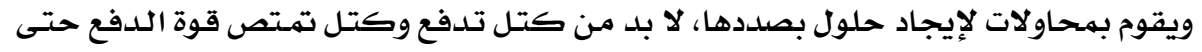

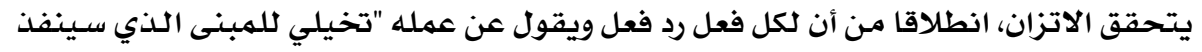

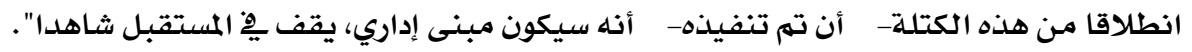

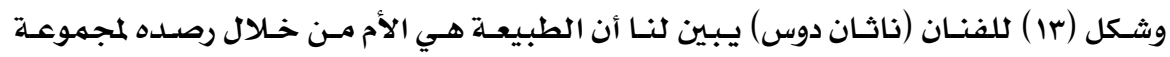

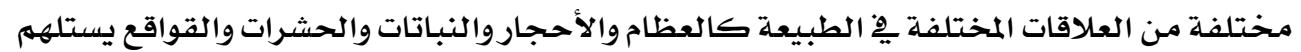

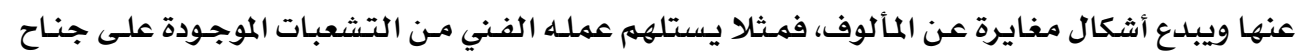
فراشة، أو حشرة ومن هنا تأتي فكرة.

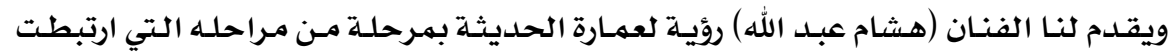

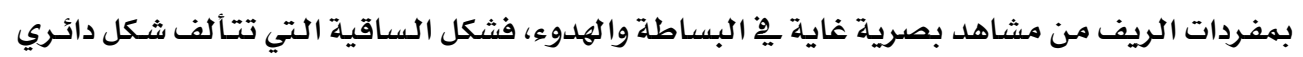

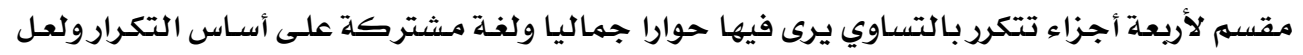

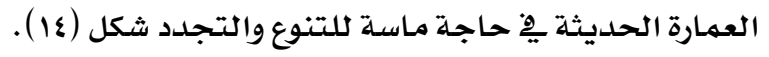

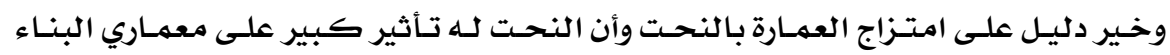

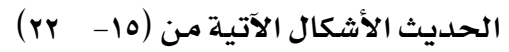




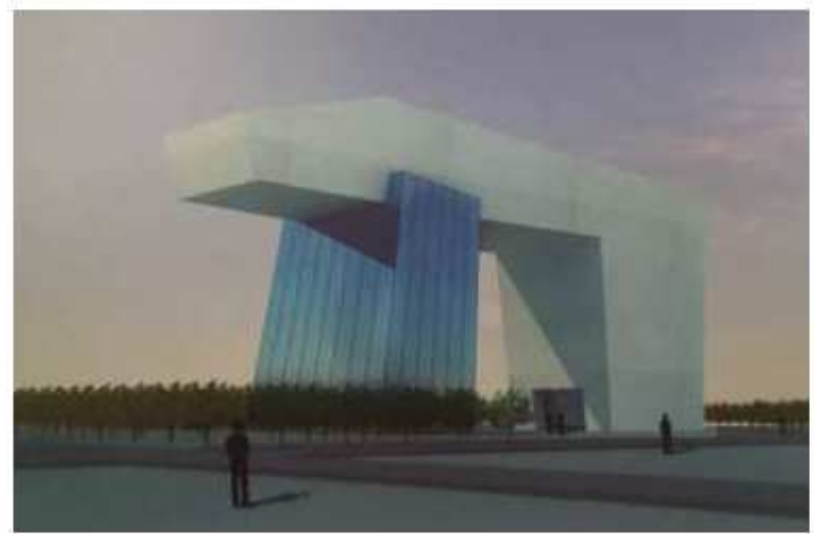

شكل (r 1) المثال علاء عبد الحمبد ( المستقبل شاهدا)

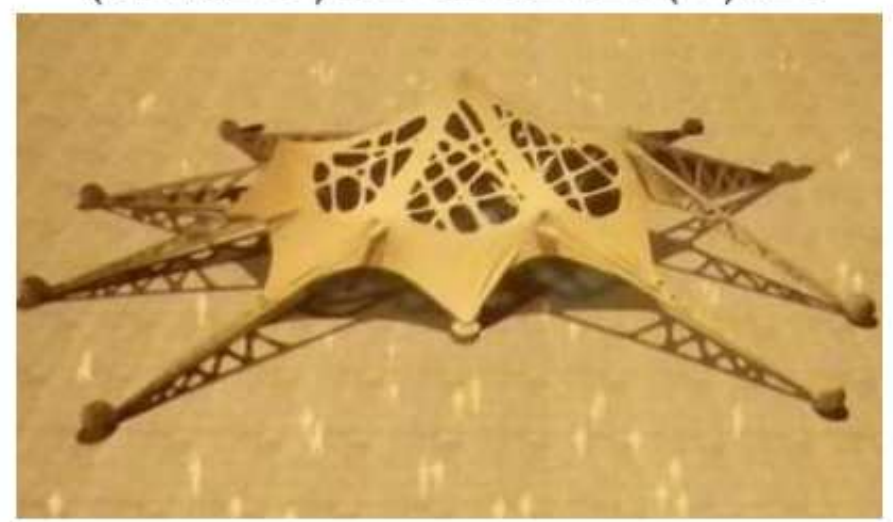

شكل (rا) نائان دوس ) ( جناح فراثة )

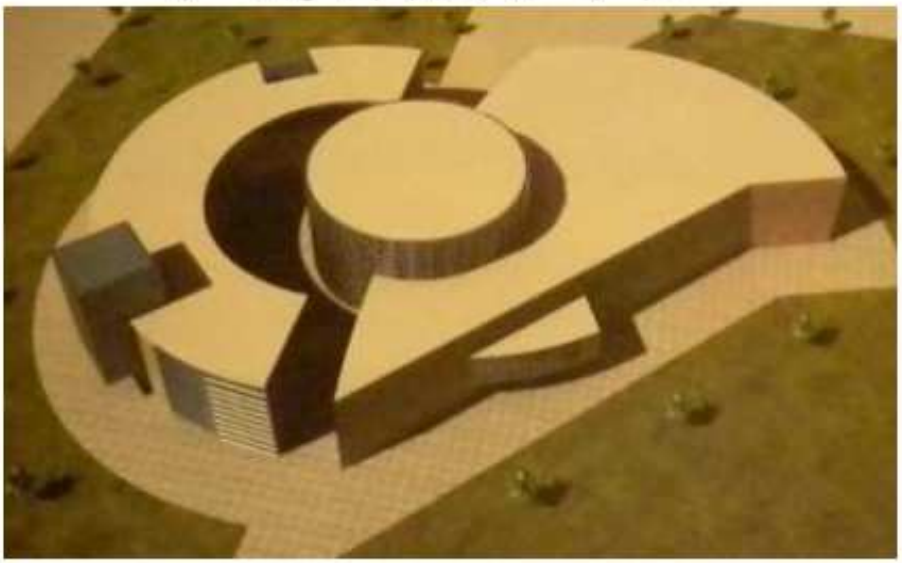

شكل (ع 1) المثُّل هشام عبد الله ( اللتوع و التجديد ) 


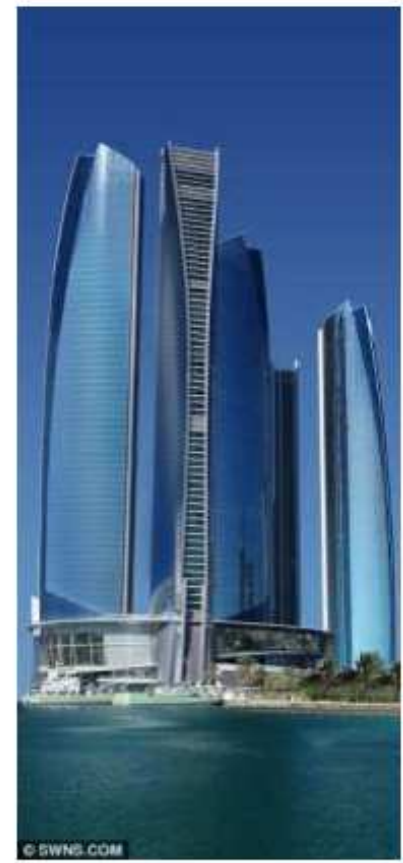

شكل (7 1) ابراج الاتحاد الامار اتبية (ابو ظبي) Y. 11

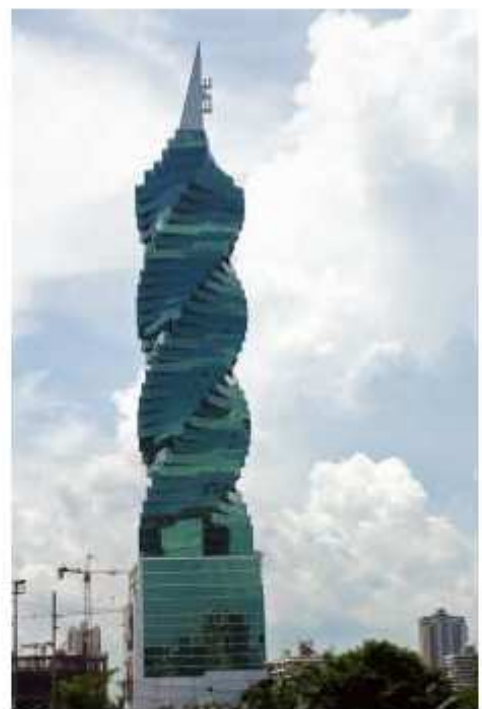

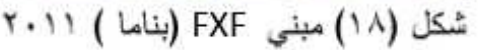

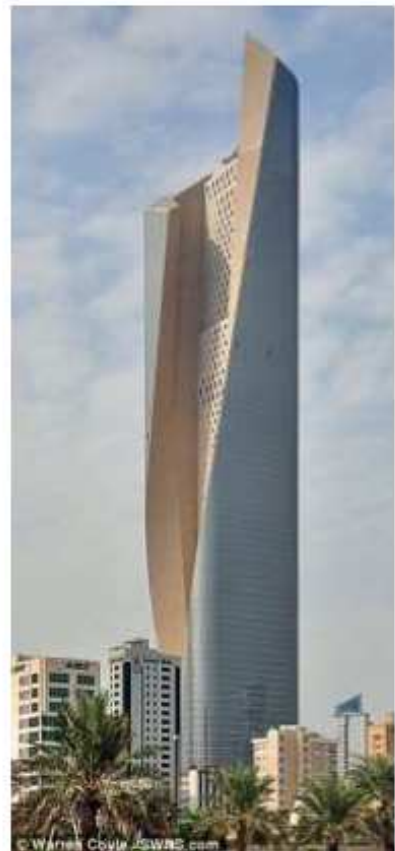

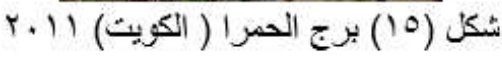

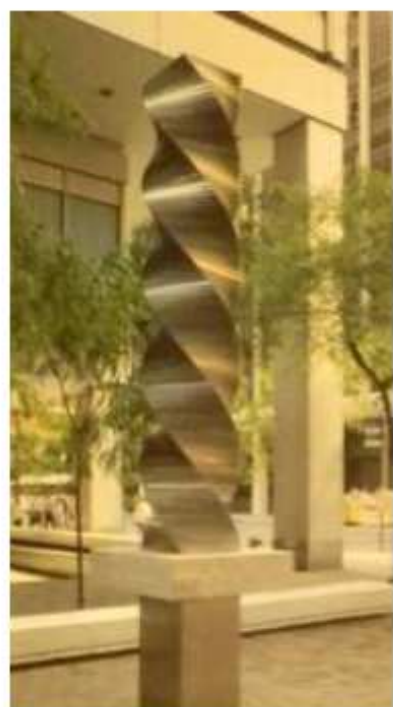

شكل (IV) عمل نحني مصدر الهام لثنكل

(1A) 


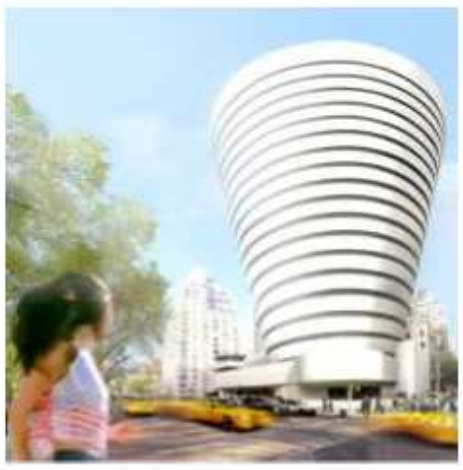

شكل (†) متحف جوجنهايِهج (نيويورك

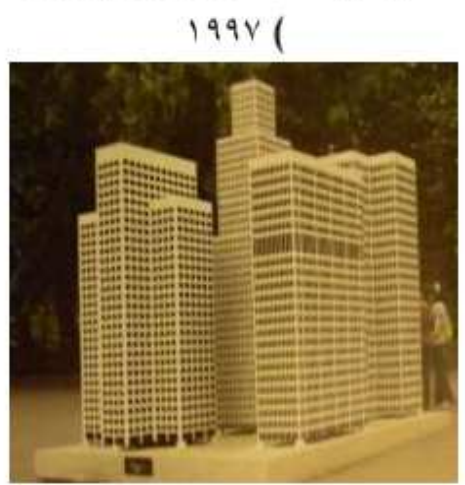

شُكل (Yr) عمل نحتي منتر ح لبناء

معار ي حديث

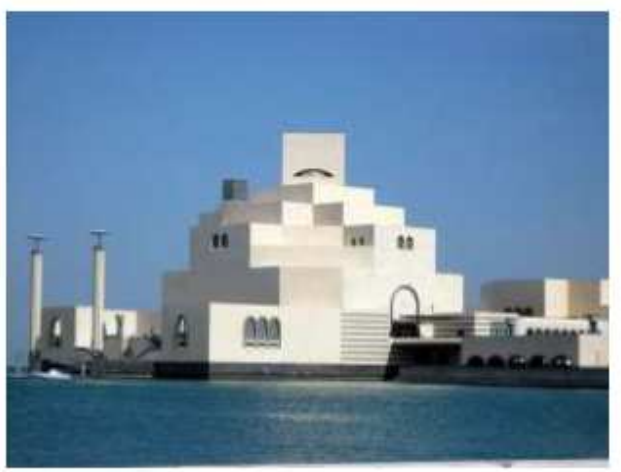

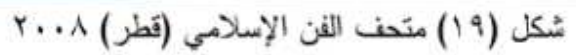

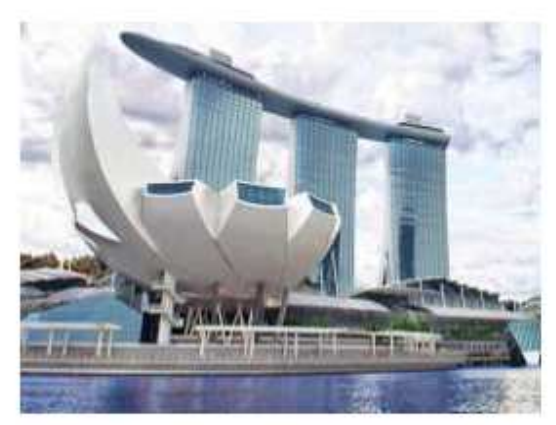

شكل (Yl) متحف علوم الفن ( مارينا باي سائدز )

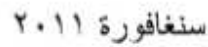

التتوصيات:

ا ـ يوصي الباحث بأن النحت والعمارة هما شيء واحد لا ليمكن الفصل بينهما .

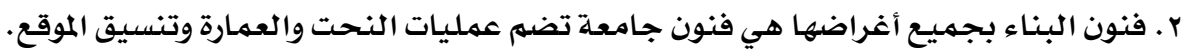

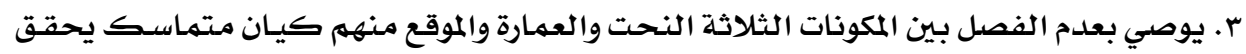
رؤية جمالية.

ـ ـ يتعاون النحات والمعماري كفريق عملي هِ عمليات التصميهم والتنفيذ والدراسـات العلمية.

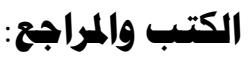

أولا: مراجع عربية:

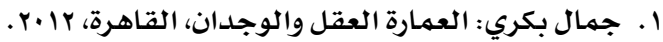

r. زكريا إبراهيم: فلسفة الفن والفكر المعاصر، مكتبة مصر، القاهرة، 1977.

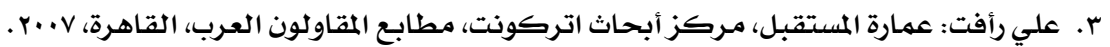




$$
\text { ع. علي رأفت: المضمون والشكل، مـركز أبحاث انتركوست، مطابع المقاولون العرب، القاهرة، V... . . }
$$

ثانيا الرسائل العلمية:

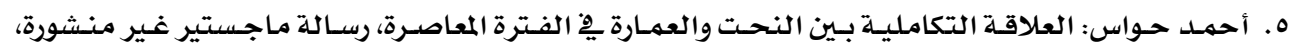
كلية التربية الفنية، جامعة حلوان، 1999 .

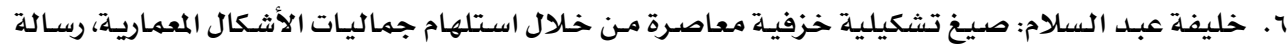
دكتوراه غير منشورة، كلية التربية الفنيلة، جامعة حلوان، 1999.

V. شحاتة أحمد عبد الرحيه: العلاقة التكاملية بين فن النحت والعمـارة ِِّ الحضارة المصرية القديهـة، رسـالة ماجستير غير منشورة، كلية الفنون الجميلة، جامعة حلوان، 1991. ^. مـروة أبو الفتوح: التشكيل النحتـي والعمـارة، رسـالة ماجستير غير منشـورة، كليـة الفنـون الجميلـة، جامعـة حلوان، V...

\section{ثالثا: مراجع أجنبية:}

1- Sbarp. D. Modern Architecture and Expressionism, Longmans, London, 1966.

2- Spade, R.panl: Rudolph thames and Hudson, London, 1977.

3- Harry N, Abrams, LNC New York, stokstad Marilyn: Art Mistory, Second, Edition, Volume, 2002.

ع - كتالوج معرض العمارة بأيدي النحاتين، قطاع الفنون التشكيلية، وزارة الثقافة، با بr. 